\title{
Viewpoint
}

\section{Carers, the community and the White Paper}

\author{
JaCQueline M. AtKinson, Senior Lecturer in Behavioural Sciences, Department of \\ Public Health, University of Glasgow, 2 Lilybank Gardens, Glasgow G12 8RZ; and \\ Denise A. Cola, Consultant Psychiatrist, Florence Street Day Hospital, Florence \\ Street, Glasgow G5
}

The role of relatives as carers of people with chronic mental illness has long been emphasised and was legitimised by Sir Roy Griffiths in his report to the Secretary of State in 1988. The White Paper (Caring for People), however, merely pays lip service to the role of the family. It does not suggest how such help might be provided. There is no reference to relatives, or even 'informal carers' (the most recent way of describing relatives), in its sections on provision of services by Social Services or the Health Service. While 'informal' is clearly used to indicate 'unpaid', it emphasises that relatives, even as carers, are not part of the formal caring process and can, therefore, be ignored as part of the team. If relatives are to be part of the service, as carers, then they need, as Griffiths and the White Paper point out, to receive support and resources to fulfil this role. But what support and services? And who is to provide them?

In the current climate of needs assessment, we must ask what are the needs of informal carers and how can these best be assessed? Although there has been research investigating the burden of care on relatives since the $1960 \mathrm{~s}$, this has not been transformed into needs assessment and our knowledge is still fragmentary.

The problems facing relatives have been traditionally divided into objective and subjective burden. Objective burden accounts for the quantifiable, measurable problem, including physical care, finances, and overcrowding. Subjective burdens are those less tangible problems of feelings and attitudes. For the past 15 years the majority of work with, and services for, families has concentrated on reducing expressed emotion in high EE families with the aim of reducing relapse in the person with schizophrenia (Leff, 1985).

Taking a slightly different approach to relatives' problems, we can divide them into two distinct types. The first group are the relatives' own problems in response to caring and the illness itself and the second are difficulties with the management of, and the caring for, the person with long term mental illness. This emphasis is important because of the bearing it has for the provision of services to relatives under the direction of the White Paper.

\section{Relatives'own problems}

These can be divided into two types: those which may affect any family member and those which are particular to the designated carer.

\section{(a) Family problems}

These can be objective and subjective, and include feelings of guilt, blame, embarrassment, anxiety, shame, bitterness, resentment, lack of privacy, overcrowding, financial responsibilities.

\section{(b) Carer problems}

It is usual in most families for one person to bear the main burden of care (Green, 1988). Such problems include the relative's perception of the caring role, their willingness or otherwise to undertake this, and loss of other roles, particularly where the ill person is a spouse.

\section{Problems in the management of caring}

These include having to live with, and deal with, the clinical problems of chronic mental illness which even trained staff can find difficult. Carers of people with long term mental illness are in the main parents and are in a different position from children caring for elderly parents. In the latter case there is a life after caring; for the parents of the long term mentally ill this is not true. One of their greatest concerns is the future. What will happen when they are no longer able to care? When they die? Neither the health nor the social services have been prepared to take this issue on board. Emphasis is still placed on provision for people coming out of hospital, who have no family involved with them. What about provision for those who, because of family involvement, are considered provided for. At least for now. 
Consideration must also be given to ethical issues (Atkinson \& Coia, 1989). Relatives' rights are rarely addressed but the rights of carers are not always congruent with the rights of the person with long term mental health problems. When advocacy for patients is barely addressed who will speak on behalf of carers?

Many of the problems of relatives result from lack of information, both about the illness itself and about management. The National Schizophrenia Fellowship, MIND, and other groups have long advocated the need for education, for patients and relatives, but this is rarely available. Although education groups for relatives are used (Hatfield, 1990), in many places education is tied to groups to reduce high EE and only reaches a small number of people.

Education groups for relatives of people with schizophrenia have been offered as a catchment wide service in South Glasgow with the aim of providing a knowledge base to enable carers to make educated choices about their role in caring and to discuss this with others in the same position. Are such groups possible within the confines of the White Paper?

One way forward is to deal with relatives in their own right, not merely as appendages of the patient. The impact of the group is not measured as clinical or social outcomes for the patient and therefore does not, if we are strict about the duties of the NHS, come under its remit, nor under the Social Services. For relatives to receive this support, under current guidelines, we need to be able to designate them 'patients' or 'clients' in their own right. This may be acceptable if such services are designated 'preventive medicine'. If we accept that some relatives/carers do require help from the NHS, ranging from medication to supportive psychotherapy, to cope in their role then a preventive service is in order. Since a common complaint of relatives is that no one will talk to them and explain what is going on, then such groups, run by
OTs or CPNs provide a good quality service more effectively, and more efficiently, than haphazard interaction with medical personnel.

The intention of the Griffiths Report and the White Paper, however, seems to want to treat relatives as part of a caring team, to support them in this role but without providing the requirement nor the resources to do this. In the section on multidisciplinary teams the relatives do not feature. Current plans by the DSS to prevent severely disabled people drawing up formal tenancy agreements with their families, and thus disallowing the severe disability premium, confirms the 'informal' nature of carer's status and the disempowered, beholden status of the disabled/ patient.

As core funding for voluntary agencies becomes ever more difficult to secure, and as they are thrust into a 'provider' role with health boards and social work departments to obtain funding, the low key, undramatic, difficult to fund educational and support work will necessarily suffer.

If community care is to work it will only do so with the acknowledged input from families as carers. Lip service has been paid to their important contribution. Now we must consider the practicalities of making both patients and carers part of the team.

\section{References}

Atkinson, J. M. \& Coln, D. A. (1989) Responsibility to carers - an ethical dilemma. Psychiatric Bulletin, 3, $602-604$.

GREEN, H. (1988) Informal Carers. London: HMSO.

HATFIELD, A. B. (1990) Family Education in Mental Illness. New York and London: Guilford Press.

LefF, J. P., Vaughn, C. (1985) Expressed Emotion in Families. New York and London: Guilford Press.

A full list of references is available on request from the authors. 